\title{
Study of endometrium by trans-vaginal sonography and it's correlation with histopathology in perimenopausal women with abnormal uterine bleeding
}

\author{
Vandana R. Saravade*, Shuchi Chaturvedi
}

Department of Obstetrics and Gynecology, Topiwala National Medical College, Mumbai, Maharashtra, India

Received: 26 July 2021

Accepted: 23 August 2021

\section{*Correspondence:}

Dr. Vandana R. Saravade,

E-mail: vandanasaravade@gmail.com

Copyright: (c) the author(s), publisher and licensee Medip Academy. This is an open-access article distributed under the terms of the Creative Commons Attribution Non-Commercial License, which permits unrestricted non-commercial use, distribution, and reproduction in any medium, provided the original work is properly cited.

\section{ABSTRACT}

Background: Objectives of the study were to study the endometrial patterns in cases of abnormal uterine bleeding (AUB) and anatomical (structural) lesions of uterus using transvaginal sonography (TVS) and endometrial histopathology and to determine the efficacy of TVS.

Methods: Cross-section study of 50 perimenopausal age group with AUB in TNMC BYL Nair hospital from Nov 2017 to Nov 2018.

Results: AUB was seen 40 to 45 years multiparous women TVS endometrial thickness (ET) T 6-10 mm (46\%), ET 11$15(22 \%)$, ET> $>15 \mathrm{~mm}(14 \%),<5 \mathrm{~mm}$ in (18\%), showed $21(42 \%)$ patients with endometrial hyperplasia on TVS, 12 (24\%) simple hyperplasia $4(8 \%)$ complex hyperplasia on histopathology fibroid $8 \%$, adenomyosis $2 \%$. endometrial polyp $6 \%$.

Conclusions: Endometrial lining exceeds $10 \mathrm{~mm}$ dilation and curettage to be done r/o endometrial hyperplasia, to study the endometrial patterns in cases of abnormal uterine bleeding and anatomical (structural) lesions of uterus using transvaginal sonography and endometrial histopathology.

Keywords: Abnormal uterine bleeding, Menstruation, Ovarian hormones

\section{INTRODUCTION}

Menstruation is a cyclical bleeding from the uterine endometrium in response to ovarian hormones which is under the control of hypothalamic-pituitary-ovarian axis. Menstrual disorders are a common indication for medical visits among women of reproductive age and menstrual bleeding affects $30 \%$ of women throughout their reproductive life time. AUB is one of the most common conditions for which women consult their gynecologists. AUB is one of the most common problems among peri and postmenopausal women. Perimenopause is the period 2-8 years preceding menopause and 1 year after final menses (WHO). However, a better practical definition is the phase preceding the onset of menopause, generally occurring around 40-50 years of age (beginning at age 47.5, lasting for 4 years) during which the regular cycle of a woman transitions to a pattern of irregular cycles. ${ }^{1}$

AUB may be defined as any variation from the normal menstrual cycle, including alteration in its regularity, frequency of menses, duration of flow, and amount of blood loss. $^{2}$

Emotional or physical stress as well as significant changes in body weight may disrupt the pituitary release of FSH and $\mathrm{LH}$ and prevent ovulation resulting in AUB. In a large number of patients, AUB occurs without any systemic causes or any organic lesions of the genital tract and for this, the term dysfunctional uterine bleeding is used. 
An international expert consensus from the FIGO menstrual disorders working group has proposed a standardized classification system for AUB to facilitate greater appreciation of the complexities of this clinical entity. ${ }^{3,4}$ This classification allows the characterization of more than one etiology in the same patient. There are 9 main categories within the classification system named for the acronym PALM-COEIN. Women with what was previously called "dysfunctional uterine bleeding" are likely to have one or more of coagulopathy, disorder of ovulation, or primary endometrial cancer. The PALM side of the classification refers to structural causes' polyp, adenomyosis, leiomyoma and malignancy that could be evaluated and diagnosed on imaging and or biopsy. The COEIN side (Coagulopathy, ovulatory dysfunction, endometrial and iatrogenic) allows consideration of underlying medical disturbances that could result in AUB.

AUB interferes significantly with a woman's physical, social, emotional quality of life. It has been seen that women with heavy bleeding of unpredictable onset take a step back from participating in routine activities, as they may require continuous access to pads and/or tampons, and they have a fear of social activity or sexual relationships because they perceive that they are on the precipice of a heavy period. In many cases, the symptoms will be relatively minor and related to self-limiting alterations in normal physiology.

The key to successful clinical management is to identify the causative factors responsible. This can be achieved by thorough clinical examination, ultrasonography and histopathological examination. The sensitivity and accuracy of these tests may be variable and considerable clinician preferences are there regarding use of diagnostic modality. Diagnostic accuracy of TVS, hysteroscopy, saline infusion sonography (SIS) and dilatation and curettage ( $\mathrm{D}$ and $\mathrm{C}$ ) has been evaluated in various studies. Each investigation is having its own advantages and disadvantages. Hysterectomy and histopathological examination of the entire uterus would provide a more accurate diagnosis but this procedure is neither desirable nor ethical to perform in all perimenopausal patients with AUB. Structural lesions may be observed in pelvic USG or TVS. But for diagnosing type of hyperplasia, histopathological examination of tissue is must. With the help of Hysteroscopy focal abnormalities suggestive of endometrial hyperplasia, a can be visualized and 'targeted hysteroscopic biopsy' may be done. But the lack of established hysteroscopic criteria for 'abnormal endometrial hyperplasia' and it's overlapping pattern with the normal late secretory endometrium, mainly in premenopausal women, is a limitation that still arouses some doubt to the reliability of this procedure. ${ }^{5}$ In addition to this hysteroscopy needs specialized equipment, skilled operator and general anesthesia.

One Meta-analysis has demonstrated that sonographic measurement of ET is an acceptable test for prediction of endometrial pathology, but it has some limitation in correctly diagnosing the type of endometrial pathology. ${ }^{6}$ In the absence any specific guidelines and recommendations we think it will be appropriate to study ET by TVS and correlate it with D and C findings. Hence this study is planned.

\section{Aims and objectives}

Aim of the study was evaluation of ET with transvaginal ultrasound and its correlation with histopathology by dilation and curettage in abnormal uterine bleeding in perimenopausal women.

Objectives of the study were to study the endometrial patterns in cases of abnormal uterine bleeding \&and anatomical (structural) lesions of uterus using transvaginal sonography and endometrial histopathology, to corelate the endometrial pattern and thickness by transvaginal ultrasound with endometrial histopathology in women with AUB and to determine the efficacy of transvaginal ultrasound in depicting the pattern of endometrium.

\section{METHODS}

\section{Study design}

It was hospital based, time bound and cross-sectional study at Nair hospital over a period from November 2017 to November 2018.

\section{Inclusion criteria}

All cases of abnormal uterine bleeding in the perimenopausal age group ( $>39$ years) admitted in TNMC, BYL Nair hospital Mumbai central were included in the study.

\section{Exclusion criteria}

The exclusion criteria of the study were-Patients with abnormal uterine bleeding in other age groups, women who have attained menopause, carcinoma of genital tract, active genital tract infection, pregnancy and related causes of bleeding PV, women on hormonal treatment at the time of first presentation, women with intrauterine device in situ, women with endocrine disorders, women with bleeding disorder and women with adnexal pathology.

\section{Study procedure}

Patients fulfilling the eligibility criteria will be followed up from admission to discharge. Necessary information will be collected in predesigned data sheet and finally findings will be compiled and analyzed using statistical analysis.

\section{Source of data collection}

This is cross-sectional study to be done on 50 patients of perimenopausal age group presenting with abnormal 
uterine bleeding in the department of obstetrics and gynecology, TNMC, BYL Nair Hospital, from Nov 2017 to Nov 2018 which will be recruited in the study after obtaining written informed consent. The 50 cases of perimenopausal women with AUB, attending the outpatient department planned for dilatation and curettage will be examined by transvaginal sonography for ET before doing dilation and curettage. Trans-vaginal sonography will be performed independent of the phase of menstrual cycle using 7.5 MHZ transvaginal transducer. The ultrasound finding that will be taken is the maximum ET measured in the sagittal plane. Transvaginal sonography and endometrial biopsy both are part of the standard care in the women with abnormal uterine bleeding.

Method to diagnose endometrial pathology by using histopathology after endometrial biopsy.

\section{Procedure of dilation and curettage}

Patient will be given total intravenous anesthesia in operation theatre. Bladder will be emptied. Under strict aseptic precaution pelvic examination will be done to know the position of cervix, size and position of the uterus. Posterior wall of the vagina retracted with Sims's bivalve vaginal speculum. Anterior lip of cervix will be caught with the vulsellum. Uterine sound will be passed to know the position and length of the uterus. The cervical canal will be serially dilated with Hagar's metal dilators of increasing size from $6-10 \mathrm{~mm}$ as required, and curettage will be done with sharp curette from all the walls of the uterus including fundus. The material obtained will be sent for histopathological examination in $10 \%$ formalin.

\section{Method to investigate ET}

ET will be measured by using transvaginal sonography in radiology department. Examination will be done using 7 . $5 \mathrm{MHz}$ vaginal micro convex transducer to know the ET.

With the uterus imaged in the longitudinal plane, ET will be measured at the thickest point between the two basal layers on the anterior and posterior uterine walls and other structural lesions associated with the uterus were also looked for. There is minimal chance of infection with transvaginal sonography as it is sterile procedure -done using condom (non-reusable) on transducer and would be done under antibiotic coverage. There is a minimal chance of bleeding due to transvaginal sonography as thickness of probe $6-8 \mathrm{~mm}$.

It is a standardized procedure. No possibility of inter observer error in TVS.

No time gap is needed between TVS and D and C. D and $\mathrm{C}$ can be immediately followed by TVS.

Patient would be paying for TVS as it is part of treatment procedure.

\section{Method and size sampling}

Simple random sampling was finalized for 50 patients, with prevalence $=66$; allowable error $=20 \%$ of prevalence; $\mathrm{z}=$ confidence interval (for $95 \%$ confidence limits, it is 1.96); $\mathrm{N}$ ( (ample size $)=51$ as per study published in Indian journal of medical research and pharmaceutical sciences July 2015.

Patients fulfilling inclusion criteria were approximately 45. So, total no. of cases in 1 year $=12 \times 4=48$. Hence sample size of 50 is taken; which is same as some other studies. ${ }^{7-9}$

Patients fulfilling the eligibility criteria will be followed up from admission to discharge. Necessary information will be collected in predesigned data sheet and finally findings will be compiled and analyzed using statistical analysis. The study was approved by the institute of ethics committee.

\section{Statistical analysis}

Statistical analysis of abnormal uterine bleeding among perimenopausal women will be done using appropriate statistical method.

All the data will be collected in Excel sheet as well as Statistical software is used. Data will be collected and descriptive statistics will be applied like mean, percentages.

\section{RESULTS}

\section{Age wise distribution}

The age wise distribution of patients shown in the Table 1 , total numbers of patients were $45,32(62 \%)$ in the age between $40-45$ years and $18(36 \%)$ in between age 46 to 50 years.

Table 1: Age wise distribution of patients, $(n=50)$.

\begin{tabular}{|lll|}
\hline Age (years) & No. of patients & Percentages (\%) \\
\hline $\mathbf{4 0 - 4 5}$ & 32 & 64 \\
\hline $\mathbf{4 6 - 5 0}$ & 18 & 36 \\
\hline
\end{tabular}

\section{ET by TVS}

In our study, 23 patients (46\%) had an ET between 6-10 $\mathrm{mm}$ and 11 patients $(22 \%)$ had an ET between $11-15 \mathrm{~mm}$. While 7 patients (14\%) have ET more than $15 \mathrm{~mm}$.

Table 2: ET by TVS method, $(n=50)$.

\begin{tabular}{|lll|}
\hline ET $(\mathbf{m m})$ & No. of patients & Percentages $(\%)$ \\
\hline $\mathbf{0 - 5}$ & 09 & 18 \\
\hline $\mathbf{6 - 1 0}$ & 23 & 46 \\
\hline $\mathbf{1 1 - 1 5}$ & 11 & 22 \\
\hline $\mathbf{> 1 5}$ & 07 & 14 \\
\hline
\end{tabular}


Table 3: Type of endometrial pattern and hyperplasia by histopathology, $(\mathrm{n}=\mathbf{5 0})$.

\begin{tabular}{|lll|}
\hline $\begin{array}{l}\text { Type of } \\
\text { hyperplasia }\end{array}$ & $\begin{array}{l}\text { No. of } \\
\text { patients }\end{array}$ & $\begin{array}{l}\text { Percentages } \\
(\%)\end{array}$ \\
\hline Atrophic & 01 & 02 \\
\hline Simple hyperplasia & 17 & 34 \\
\hline $\begin{array}{l}\text { Complex } \\
\text { hyperplasia }\end{array}$ & 04 & 08 \\
\hline Proliferative & 15 & 30 \\
\hline Secretory & 13 & 26 \\
\hline
\end{tabular}

\section{Clinical presentation}

Table 4: Clinical presentation of patients, $(n=50)$.

\begin{tabular}{|lll|}
\hline $\begin{array}{l}\text { Various } \\
\text { menstrual } \\
\text { patterns }\end{array}$ & $\begin{array}{l}\text { No. of } \\
\text { patients }\end{array}$ & $\begin{array}{l}\text { Percentages } \\
(\%)\end{array}$ \\
\hline Menorrhagia & 21 & 42 \\
\hline Polymenorrhoea & 13 & 26 \\
\hline Menometrorrhagia & 15 & 30 \\
\hline Oligomenorrhoea & 1 & 2 \\
\hline
\end{tabular}

\section{Correlation of histopatholgical findings and TVS findings}

Table 5: Correlation of histopatholgical findings and TVS findings, $(\mathrm{n}=\mathbf{5 0})$.

\begin{tabular}{|c|c|c|c|c|}
\hline $\begin{array}{l}\text { Thickness by TVS } \\
\text { histopathology } \\
\text { changes }\end{array}$ & $0-5$ & $6-10$ & $11-15$ & $>15$ \\
\hline Atrophic & 1 & & & \\
\hline Simple hyperplasia & & 5 & 9 & 3 \\
\hline $\begin{array}{l}\text { Complex } \\
\text { hyperplasia }\end{array}$ & & & & 4 \\
\hline Proliferative & 8 & 7 & & \\
\hline Secretory & & 11 & 2 & \\
\hline
\end{tabular}

In our study, $21(44 \%)$ patients showed endometrial hyperplasia and $15(30 \%)$ patients showed proliferative type of endometrium. Endometrial hyperplasia is seen mainly in patients having ET $>10 \mathrm{~mm}$.

\section{Morphology of endometrial hyperplasia}

Table 6: Type of hyperplasia, $(n=21)$.

\begin{tabular}{|l|l|l|}
\hline $\begin{array}{l}\text { Type of } \\
\text { hyperplasia }\end{array}$ & $\begin{array}{l}\text { No. of } \\
\text { patients }\end{array}$ & $\begin{array}{l}\text { Percentages } \\
(\%)\end{array}$ \\
\hline $\begin{array}{l}\text { Simple } \\
\text { hyperplasia }\end{array}$ & 17 & 80.95 \\
\hline $\begin{array}{l}\text { Complex } \\
\text { hyperplasia }\end{array}$ & 3 & 14.28 \\
\hline $\begin{array}{l}\text { Atypical } \\
\text { hyperplasia }\end{array}$ & 1 & 4.76 \\
\hline
\end{tabular}

Among 22 patients of endometrial hyperplasia, only 1 patient $(4.76 \%)$ had atypical hyperplasia. Majority (81\%) had simple hyperplasia.

\section{Correlation between ET on TVS and endometrial hyperplasia}

Table 7: Correlation between ET on TVS and endometrial hyperplasia, $(n=50)$.

\begin{tabular}{|llll|}
\hline $\begin{array}{l}\text { ET } \\
(\mathbf{m m})\end{array}$ & $\begin{array}{l}\text { No. of } \\
\text { patients }\end{array}$ & $\begin{array}{l}\text { Endometrial } \\
\text { hyperplasia }\end{array}$ & $\begin{array}{l}\text { Percentages } \\
(\%)\end{array}$ \\
\hline $\mathbf{0 - 5}$ & 09 & 0 & \\
\hline $\mathbf{6 - 1 0}$ & 23 & 5 & 23.8 \\
\hline $\mathbf{1 1 - 1 5}$ & 11 & 9 & 42.86 \\
\hline $\mathbf{> 1 5}$ & 07 & 7 & 33.33 \\
\hline
\end{tabular}

All the 7 patients having ET more than $15 \mathrm{~mm}$ found to be having endometrial hyperplasia. While out of 11 patients having ET 11-15 mm, 9 patients were having endometrial hyperplasia. None of the patient with ET less than $5 \mathrm{~mm}$ was having endometrial hyperplasia.

\section{Parity}

Table 8: Parity of the patient, $(n=50)$.

\begin{tabular}{|c|c|c|}
\hline Parity & No. of patients & $\begin{array}{l}\text { Percentage } \\
(\%)\end{array}$ \\
\hline 0 & 2 & 4 \\
\hline 1 & 9 & 18 \\
\hline 2 & 12 & 24 \\
\hline 3 & 8 & 16 \\
\hline 4 & 10 & 20 \\
\hline 5 and above & 9 & 18 \\
\hline
\end{tabular}

\section{DISCUSSION}

Histological variation can be seen in endometrium according to age of women, phase of menstrual cycle and any another specific pathology. ${ }^{10}$ AUB is primarily a change from normal menstrual pattern. The $50 \%$ of perimenopausal women are affected by AUB. Currently, the focus has shifted to TVS as a simple, non-invasive alternative method to hysteroscopy and curettage. The advance of high-resolution transvaginal probes has revolutionized the ability to visualize the endometrium. Transvaginal sonography is an accurate instrument for the evaluation of the endometrium in menstruating as well as postmenopausal women. The use of TVS has reduced risks and burden to patients, as well as costs. ${ }^{11}$

The routine blood and serological investigations conducted for abnormal uterine bleeding include complete blood count, platelet count, prothrombin time (PT), activated partial thromboplastin time (APTT) and liver function test, carried out to find any coagulation and bleeding disorders. In women of reproductive age group, 
human chorionic gonadotropin (HCG) levels may be evaluated to rule out pregnancy. Thyroid function test, follicle stimulating hormone (FSH), luteinizing hormone (LH), prolactin levels are estimated to find endocrinal cause. To find out structural pathology or endometrial cause imaging techniques can be used such as pelvic ultrasound (USG), transvaginal USG and Hysteroscopy, saline infusion sonography. Dilation and curettage can be used as diagnostic as well as therapeutic procedure. Combined approach with noninvasive blood investigations and imaging techniques may help in finding the cause.

The present study was conducted in 50 perimenopausal women mainly in age group of 40-50 years. It has found in present study that AUB is seen mainly in age group 40-45 yr. Shajitha et al has also done the study on same age group and their observations regarding incidence is almost similar with our study. ${ }^{12}$ In the present study, the highest incidence of AUB was seen in which is in concordance with the studies done by Mehrotra et al, Pilli et al, Zarawar et al and Archana et al. ${ }^{13-16}$

The lowest incidence was seen in nulliparous women in the present study. By these observations, it may be implied that incidence of AUB is highest in parous women. Shajitha et al has also the observed the same findings.

Table 4 showed distribution of cases according to clinical presentation, out of 50 cases maximum no of patient (42\%) presented with heavy menstrual bleeding, this is as per revised terminology by AICOG which correspond to menorrhagia, while frequent bleeding (polymenorrhea) in $(26 \%)$ of patient and heavy prolonged bleeding (Menometrorrhagia) in (4\%) of patient. Choudhary et al has also reported that majority of patients (50\% of cases) having menorrhagia. Bleeding pattern was comparable to the study done by Pillai et al who reported $46.5 \%$ patients having menstrual complaints of menorrhagia. ${ }^{17}$ Panda's had $60 \%$ cases of menorrhagia followed by Polymenorrhagia and Metrorrhagia. Tahir et al, Bigrigg et al Menorrhagia $40.75 \%$, PMB $30.75 \%$ Kekelci et al Menorrhagia 21\%, PMB 13.3\%, menometrorrhagia $65.7 \%$.

While analyzing structural lesions by USG, it has been found that out of 50 cases 4 patients were having fibroids, 2 patients' adenomyosis and 3 patients were having polyps.

The 4 patients were having history of use of OC pills in the past, and one patient had the history of SERM use in past. Five patients were having family history of endometrial carcinoma.

In our study, 21 patients had endometrial hyperplasia. There was no evidence of hyperplasia when the ET was less than $5 \mathrm{~mm}$. Out of 50 patients of AUB, proliferative endometrium was seen in $30 \%$, secretory endometrium in $26 \%$, endometrial hyperplasia in $42 \%$, and atrophic in $2 \%$ cases. Common type of hyperplasia noted in our study is
Simple hyperplasia which is in line with Thulasi et al and Shrestha et al. ${ }^{18,19}$ Table 2 shows correlation of patient's menstrual symptom with ET. Out of 50 cases of abnormal uterine bleeding, maximum no of patient $(46 \%)$ had ET between $6-10 \mathrm{~mm}$, followed by $11-15 \mathrm{~mm}$ of ET in $21 \%$ cases. Thulasi et al, 21 has correlated ET by TVS and histopathology. In their study 30 patients had endometrial hyperplasia when the ET exceeded $10 \mathrm{~mm}$. There was no evidence of hyperplasia when the ET was less than $10 \mathrm{~mm}$. But in our study, we found that 5 patients having ET 5-10 $\mathrm{mm}$ were presented with hyperplasia. ${ }^{18,19}$

In the present study, analysis of patient's histopathological findings showed Endometrial hyperplasia in 21 cases, on comparison with histopathology report 7 cases having ET more than $15 \mathrm{~mm}$ were truly diagnosed on TVS. In a group where ET is $11-15 \mathrm{~mm}$ out of 11 cases 9 patients were confirmed with histopathology and 2 cases missed. According to WHO classification of tumours the endometrial hyperplasia is classified as simple or complex based on the absence or presence of architectural abnormalities like glandular complexity and crowding, further designated as atypical if they show nuclear atypia. ${ }^{20}$

Vercellini et al has noted that "considering the good specificity and high negative predictive value, transvaginal ultrasonography may be suggested as the initial investigation in menorrhagic patients, limiting hysteroscopy to cases with positive or doubtful sonographic findings.". ${ }^{21}$ The main disadvantage of TVS is the technique of measuring the endometrium and experience of the operator which will affect the measurements.

Thus, TVS can be used as first line imaging modality for the evaluation of AUB. It is non-invasive safe and helps in diagnosing certain causes of the AUB. Present study is having certain limitations as it is a small sample study. Also, we have not compared between different modalities of imaging. So, regarding choice of investigation, conclusive remarks cannot be given. Moreover, a detailed study with comparison between different techniques may help further.

From the point of view management either medical or surgical therapy can be considered. Endometrial ablations are getting more popularity. And hysterectomy can be used as a final resort. Few of the patients also respond to the hormonal therapy.

\section{CONCLUSION}

Based on the findings of the above study, it can be concluded that in abnormal uterine bleeding, the first investigation should be transvaginal ultrasound. If the ET exceeds $10 \mathrm{~mm}$, a dilatation and curettage procedure is to be done to rule out any endometrial hyperplasia. TVS allows detection an endometrial pathology in majority of cases. TVS is comparatively safe and non-invasive method and does not require any anesthesia so it can be used as the 
first line diagnostic tool in investigating AUB in perimenopausal age group.

Funding: No funding sources

Conflict of interest: None declared

Ethical approval: The study was approved by the Institutional Ethics Committee

\section{REFERENCES}

1. Shobhitha GL, Indira Kumari V, Priya PL, Sundari TB. Endometrial Study by TVS and It's Correlation with Histopathology in Abnormal Uterine Bleeding. J Dental Med Sci. 2015;14(4):21-32.

2. Woolock JG, Critchley HO, Munro MG, Broder MS, Fraser IS. Review of the confusion in current and 80. Fertil Steril. 2008;90(6):2269-80.

3. Munro MG, Crissstchley Ho, Broder MS, Eraser IS. For the FIGO working group on Menstrual Disorders. FIGO classification system (PALM-COEIN) for causes of abnormal uterine bleeding in non-gravid women of reproduction age. Int $\mathbf{J}$ Gynacol obstet. 2011;113:3-13.

4. Stein G Sr, Zeltser, Horan CK, Snyder JR, Schwartz LB. Ultra-sonography-base triage for perimenopausal patients with abnormal uterine bleeding. AMJ obstet Gynecol. 1997; 177:102-8.

5. Subhankar D. Abnormal Uterine Bleeding in PeriMenopausal Age: Diagnostic Options and Accuracy. J Obstetr Gynecol India. 2011;189-94.

6. Gupta JK, Chien PF, Voit D. Ultrasonographic endometrial thickness for diagnosing endometrialpathology in women with postmenopausal bleeding: a meta-analysis. Acta Obstet Gynecol Scand. 2002;81:799-816.

7. Choudhary J. Evaluation of abnormal uterine bleeding with transvaginal sonography and hysteroscopy in perimenopausal women. Int $\mathbf{J}$ Reprod Contracept Obstet Gynecol. 2017;6(8):3607-13.

8. Maboud NMA, Elsaid HH. Role of transvaginal ultrasonography and colour Doppler in the evaluation of postmenopausal bleeding. Egypt J Radiol Nuclear Med. 2015;46:235-43.

9. Shobhitha GL, Indira Kumari V, Priya PL, Sundari TB. Endometrial Study by TVS and It's Correlation with Histopathology in Abnormal Uterine Bleeding. J Dental Med Sci. 2015;14(4):21-32.

10. Srikanth S. Histopathological study of endometrial lesions in patients in a Tertiary care hospital in north Telangana. Int J Sci Res. 2015;7(5):2277.
11. Sur D, Chakravorty R. Correlation of Endometrial Thickness and Histopathology in Women with Abnormal Uterine Bleeding. Reprod Syst Sex Disord. 2016;5:192.

12. Shajitha S. Tthe study of endometrial thickness by transvaginal USG with its Histopathology correlation in abnormal uterine bleeding. Int $\mathrm{J}$ Current Med Pharmaceutical Res. 2017;3(10):2487-90.

13. Mehrotra VG, Mukherjee K, Pandey M, Samanth V. Abnormal uterine bleeding (a review of 150 cases). J Obstet Gynecol India. 1972;22:684-9.

14. Pilli GS, Seth SB. Dysfunctional uterine bleeding-a study of 100 cases. J Obstet Gynecol of India. 2002;52(3):87-9.

15. Zarawar MP, Bolde S. Histopathological study of endometrium in dysfunctional uterine bleeding. Solapur Med J. 2005;1(4).

16. Archana B, Michelle F. Evaluation and histopahological correlation of abnormal uterine bleeding in perimenopausal women. J Bombay Hosp. 2010;52:69-72.

17. Pillai SS. Sonographic and histopathological correlation and evaluation of endometrium in perimenopausal women with abnormal uterine bleeding. Int J Reprod Contracept Obstet Gynecol. 2014;3(1):113-7.

18. Thulasi P, Balakrishnan R, Shanthi M. Correlation of endometrial thickness by Trans-Vaginal Sonography [TVS] and histopathology. Indian J Obstetr Gynecol Res. 2018;5(1):44-8.

19. Shrestha P, Shrestha S, Mahato V. Is Ultrasonography helpful in abnormal uterine bleeding? Asian J Med Sci. 2018;9(2):31-5.

20. Tavassoli FA, Devilee P. Pathology and genetics of tumours of the breast and female genital organs. Tumors of the uterine corpus. In WHO classifications of tumours. IARC Press, Lyon France. 2003;221-32.

21. Vercellini P, Cortesi I, Oldani S. The role of transvaginal ultrasonography and outpatient diagnostic hysteroscopy in the evaluation of patients with menorrhagia. Hum Reprod. 1997;12:1768-71.

Cite this article as: Saravade VR, Chaturvedi S. Study of endometrium by trans-vaginal sonography and its correlation with histopathology in perimenopausal women with abnormal uterine bleeding. Int J Reprod Contracept Obstet Gynecol 2021;10:3554-9 